\title{
Intermédialités
}

Histoire et théorie des arts, des lettres et des techniques

Intermediality

History and Theory of the Arts, Literature and Technologies

\section{Transference and Transparency: Digital Technology and the Remediation of Cinema}

\section{Jay David Bolter}

Numéro 6, automne 2005

Remédier

Remediation

URI : https://id.erudit.org/iderudit/1005503ar

DOI : https://doi.org/10.7202/1005503ar

Aller au sommaire du numéro

Éditeur(s)

Centre de recherche sur l'intermédialité

ISSN

1705-8546 (imprimé)

1920-3136 (numérique)

Découvrir la revue

Citer cet article

Bolter, J. D. (2005). Transference and Transparency: Digital Technology and the Remediation of Cinema. Intermédialités / Intermediality, (6), 13-26.

https://doi.org/10.7202/1005503ar
Résumé de l'article

Les nouveaux objets numériques, en particulier les jeux vidéos et les jeux par ordinateurs, ont remis en cause le statut culturel que le cinéma a occupé pendant des décennies. Cette remise en cause a donné lieu à une anxiété vis-à-vis des nouveaux médias, qui se trouve réfléchie dans une série de films des années 1990, notamment eXistenZ et The Matrix. Les cinéastes

hollywoodiens ont répondu à ce " défi numérique » en adoptant une double stratégie: ils ont intégré les effets spéciaux générés par ordinateur, tout en maintenant une adhésion au récit linéaire narratif et à la représentation transparente. Récemment, le DVD a amené l'industrie cinématographique à explorer des formes hybrides de représentation et même d'interactivité. 


\title{
Transference and Transparency: Digital Technology and the Remediation of Cinema
}

\author{
Jay David Bolter
}

T o claim that we are living in the era of "late cinema" is not to say that cinema is dying. In fact, cinema has entered a peculiar phase in which it seems both past its prime and vigorous at the same time. Like Frederic Jameson's late capitalism, ${ }^{1}$ indeed as a part of global capitalism, late cinema is flourishing. Nevertheless, popular film feels today like a late media form. It proceeds according to formulas, and it is marketed, perhaps to a greater degree than ever before, as a commodity by the entertainment industry. Film seems to have reached a kind of ripe old age, which is quite the opposite of the cultural position of both popular and experimental film in, say, the 1920s. This is the era of late cinema, as it is the late age of print. $^{2}$ This tacit, sometimes explicit, understanding hangs over the various forms of both film and print and shapes how they are received in our culture today. In both cases it is digital technologies of communication and representation that cause film and print to seem obsolescent.

The reactions of writers and print publishers to the challenge of digital media would be the subject for another essay. We are concerned here with the reactions by filmmakers and the film industry to the challenge posed by such digital forms as computer games, interactive and enhanced television, and hypermedia and the World Wide Web. For the past decade and more, the film industry has been engaging in a particular form of intermediality that could be called "remediation."3 If intermediality is in general the study of the relationships of one

1. Fredric Jameson, Postmodernism, Or the Cultural Logic of Late Capitalism, Durham, North Carolina, Duke University Press, 1991.

2. Jay David Bolter, Writing Space: The Computer, Hypertext, and the Remediation of Print, Mahwah, New Jersey, Lawrence Erlbaum Associates, 2001.

3. Jay David Bolter and Richard Grusin, Remediation: Understanding New Media, Cambridge, Massachusetts, MIT Press, 1999. See also Jay David Bolter and Diane 
medium or media form to others, remediation describes a particular relationship in which homage and rivalry are combined. In a remediating relationship, both newer and older forms are involved in a struggle for culture recognition.

In this case, the process of remediation is mutual: digital media (particularly computer and video games) are remediating film, and film is remediating these digital forms in return. Producers of digital media want to challenge the cultural status of conventional film and television by appropriating and refashioning the representational practices of these older forms. Film and television producers are ready to appropriate digital techniques in turn, whenever they can do so while retaining what they regard as the key qualities of their systems of representation. In these processes of mutual appropriation, the contested field is the construction of the authentic or the real: the question becomes which media form can offer the viewer a more compelling representation of the real. Remediation can be thought of as a process of transfer, in which the definition of the real or the authentic is transferred from one form to another. The transference is always a translation in the sense that the authentic or the real is redefined in terms appropriate to the remediating media form.

For example, a computer game may borrow the representational practices of film and at the same time claim that the interactive play provided by the game constitutes a more compelling experience than that of viewing a film. Film answers by borrowing some digital techniques, while insisting on the superiority of its own brand of visual storytelling. If computer games and interactive television appear to offer new narrative possibilities, film has largely rejected these possibilities (or at least reinterpreted them) and constructed itself (ironically) as a popular, cultural rearguard. Filmmakers continue to promise their viewers authenticity through the traditional techniques of plotting, acting, and continuity editing. This promise is ironic because mainstream film has by definition never been an elite art form. As a popular form, film would seem to be open to experimentation and novelty. For their part, digital media forms are not obvious candidates for the avant-garde. Although there is a relatively small but vigorous digital art community, computer and video games are the digital forms with which most people are familiar. With traditional movies and computer games, we are witnessing a competition between massively popular media forms. Every since modernism, the "avant-garde" has always referred to a small group over against the predominant cultural forms. Now, however, new media theorists parency, Cambridge, Massachusetts, MIT Press, 2003. 
invoke a modernist rhetoric when they insist that new media, such as digital games, must break with the constraining traditions of film and television.

\section{CONTEMPORARY FILM AS REMEDIATION}

Despite the continued success of mainstream film, there remains a real anxiety about the future of film in an increasingly digital media landscape, an anxiety that Paul Young has characterized as "cyberphobia" in Hollywood films of the 1990s. ${ }^{4}$ The last decade of the zoth century was the time in which Hollywood became aware of the magnitude of the challenge posed by digital media technology to its traditional representational practice. In the early 2000 , cyberphobia has by no means entirely subsided; however, the film industry is increasingly ambivalent, as it both fears and seeks to embrace digital representational practices.

We might compare Hollywood's cyberphobia to its response to a previous threat, the rapid rise of television in the 1950 accompanied by a decline in movie attendance in the United States. Film responded in that case with a series of technical innovations: the widespread use of color, the changed aspect ratio through cinemascope and other lens and display technologies, and a brief flirtation with 3D. 5 These innovations allowed film to reclaim its status as a representational practice that was "true to life" and "larger than life" at the same time. Today the threat comes principally from another small-screen media form: a video display with keyboard and joystick. Although the success of digital games (or for that matter the World Wide Web) has not diminished Hollywood ticket sales, nevertheless filmmakers and the film industry seem to be concerned with a loss of cultural (and perhaps eventually economic) status.

Their response has been two-fold. On the one hand, Hollywood producers and filmmakers have embraced digital technology; they have enthusiastically adopted computer-graphic techniques in order to produce "blockbuster" films laden with special effects. This strategy is obviously different from the response to television in the 1950s. Digital technology is today being used to redefine the look of film and make possible a new degree of spectacle: the point is to appropriate the flexibility and vividness of computer graphics for traditional film. The strategy began with the original Star Wars (George Lucas, 1977) and continued at an accelerating pace throughout the 1980s and 1990s, until each new Hollywood blockbuster

4. Paul Young, "The Negative Reinvention of Cinema: Late Hollywood in the Early Digital Age," Convergence, Vol. 5, No. 2, summer 1999, p. 24-50.

5. See David A. Cook, A History of Narrative Film, New York, W. W. Norton \& Co., 1990 [1981], p. 480 et sq. 
seems required to have more special effects than its predecessors. Hollywood is seeking to blunt the potentially disruptive impact of computer graphics by using the computer to improve film's traditional style of transparent representation.

Computer graphic techniques have already changed the representational style of feature-length animated films. Beginning with Toy Story (John Lasseter, 1995) and Toy Story 2 (John Lasseter, 1999) and continuing to the present with the Shrek films, Finding Nemo (Andrew Stanton, Lee Unkrich, 2003), and The Incredibles (Brad Bird, 2004), Hollywood animation has come to rely on 3D computer graphics to define a filmic space that is markedly different from that of $2 \mathrm{D}$ cell animation. This is not the case for live-action film. Here computer graphics are composited into traditional footage and deployed along with miniatures, animatronics, stop-motion animation and so on, in order to create a seamless whole in which the marks of the digital technology are effaced. Often, the result is meant to seem completely "natural:" that is, the viewer is invited to imagine that everything he or she sees on the screen is a record of live-action filming. Thus James Cameron's Titanic (1997) had numerous special effects, but the final spectacle looked as if it were a faithful reflection of the voyage and sinking of a real ship. The use of computer effects was completely consonant with the director's reported obsession with authenticity of detail in the mise-en-scène. In other mainstream films, the special effects are foregrounded and elided at the same time-for example, in another Cameron film, Terminator 2: Judgment Day (1991). In this case, the T10oo robot is capable of changing shape: it can change its molecular structure so as it appear to be part of the tile floor and then emerge out of the floor to murder a guard. This shape-shifting is depicted through the then-unfamiliar technique of computer graphic morphing. Although such striking visual effects can in no sense be regarded as realistic, the goal remains to make them look believable: that is, if a robotic creature could change its molecular structure, this is what it would look like as it emerged from the floor. The Lord of the Rings trilogy (Peter Jackson, 2001, 2002, 2003) is a similar case: here the computer graphics are sometimes foregrounded (e.g. when used to represent supernatural events and beings) and sometimes effaced (e.g. when used to enlarge the scope of battle scenes), but the goal is seamless representation: everything the viewer sees should plausibly belong to the world of Middle Earth.

In films from Terminator 2 to The Lord of the Rings, the smooth surface of the Hollywood style is not threatened. With the exception of certain genres of comedy and perhaps the musical, mainstream Hollywood cinema has been reluctant to remind the viewer of the multiple sources and constructed nature of the spectacle, reluctant to acknowledge the intermediality or hybridity of film. To 
acknowledge hybridity has been the mark of the avant-garde or "art" film-e.g. the films of Peter Greenaway or Chris Marker rather than those of James Cameron or Steven Spielberg. ${ }^{6}$ Popular film has maintained its allegiance to the representational practices that made it immensely popular throughout the 2 oth century and has been in this sense more conservative than rock music and television, both of which now offer to mainstream audience some highly self-referential and hybrid forms. The most obvious example is the hybrid of rock music and television, the music video. Although music videos also incorporate film techniques, the result sometimes looks more like Un chien Andalou (Luis Buñuel, 1929) than any mainstream Hollywood product. In recent years there is some evidence that Hollywood film is beginning to follow television here and become more receptive to hybridity. But before elaborating on this development, I would like to examine the reaction of film in the 1990 s in more detail.

The widespread adoption of computer-graphics in film may have helped to ensure the continued success of the Hollywood film, but it did not allay Hollywood's cyberphobia. This anxiety emerged in a series of films that are among the most interesting products of this era of late cinema-films that can fairly be called popular allegories of the digital. Paul Young has discussed several such films, including Lawnmower Man (Brett Leonard, 1992), The Truman Show (Peter Weir, 1998) and Strange Days (Kathryn Bigelow, 1995).7 I would like to examine Strange Days in more detail and to add eXistenZ (David Cronenberg, 1999), and The Matrix (Andy Wachowski, Larry Wachowski, 1999) to the list.

Directed by Kathryn Bigelow, Strange Days offers a vision of the (then) near future in which the government has perfected a form of Virtual Reality, the so-called "wire," that puts other people's perceptions directly into the user's mind. In the apocalyptic last days before the year 2000, the wire is being used for black market purposes by the main character, Lenny, who sells his customers the opportunity to experience sex and violence without the attendant personal dangers. In a scene early in the film, Lenny describes the wire to a potential customer, a timid lawyer who is attracted to these vicarious experiences. Lenny tells him: "This is not like... TV, only better. This is life, a piece of somebody's life. You are there, you're doing it, you're seeing it, you're hearing it, you're feeling it." Lenny is claiming that the wire is a medium that is not a medium at all. Unlike

6. See Yvonne Spielmann, Intermedialität. Das System Peter Greenaway, München, Wilhelm Fink Verlag, 1998. See also Petr Szczepanik, "Intermediality and (Inter)media: Reflexivity in Contemporary Cinema," Convergence, Vol. 8, No. 4, winter 2002, p. 29-36.

7. Paul Young, "The Negative Reinvention of Cinema," p. 27-30, p. 42-45. 
television, the wire offers "real" or authentic experiences-not re-presentations, but direct presentations of life. Transferring lived experience from one subject to another, the wire is a medium that does not mediate.

In making this pitch, Lenny posits in his client (or in general in his culture at the end of the zoth century) a desire for immediacy. Does our culture in fact have such a desire for immediacy that could be satisfied by a perfectly transparent medium? New media theorists and computer interface designers have proposed the perfect transparent interface as the ultimate goal of virtual reality. In the near term the desire for transparency takes the form of the assumption by interface designers that the interface should disappear: that it must not intrude into the user's consciousness as he or she works with a computer application. The user should look through the interface, rather than at the interface. ${ }^{8}$ Many saw in virtual reality the opportunity to achieve this transparency. As early as 1991, for example, interface designer Meredith Bricken wrote an article entitled "Virtual Worlds: No Interface to Design"; her premise was that virtual reality would make it possible to design computer applications that have no interface, in the sense that the user could interact directly with a virtual environment as if it were her physical world. 9

In the longer term, theorists who are considering the digital medium as a new form of art and entertainment do envision a perfected form of fully immersive, fully interactive virtual reality. In the most important study of the potential of interactive digital media, Janet Murray specifically appeals to the holodeck from the television series Star Trek (1966-1969) as the ultimate goal. ${ }^{10}$ As a medium, the holodeck is transparent to its experienced content; the user cannot tell the difference between the holodeck and the physical world. The wire in Strange Days is like the holodeck except that it foregrounds the reality of interior consciousness: the user sees the world through the senses of another person. In fact, Strange Days, The Matrix, and (arguably) eXistenZ are all "VR films," in that they explore the consequence of a perfected virtual reality technology. These films induce anxiety by imagining that the enormous technological hurdles to experiential VR have already been overcome. They portray what Ellen Strain has

8. See Jay David Bolter and Diane Gromala, Windows and Mirrors, p. 30-56.

9. Meredith Bricken, "Virtual Worlds: No Interface to Design," in Cyberspace: First Steps, Michael Benedikt (ed.), Cambridge, Massachusetts, MIT Press, 1992, p. 363-382.

10. Janet Murray, Hamlet on the Holodeck, Cambridge, Massachusetts, MIT Press, 1997. 
called "virtual, virtual reality," a Hollywood fantasy rather than any current or foreseeable technology. ${ }^{11}$

Strange Days offers virtual reality as a medium to replace all other media. When Lenny says that the wire is "not TV only better," his very words bring to mind the relationship of the wire to television and implicitly to other media. The wire as a symbol for digital new media is claiming to be TV only better, or rather film only better. This is characteristic of a remediating relationship, in which the remediating form appears to deny its dependence on the other form, yet in the very act of denial in fact affirms that dependence. In this case, Strange Days examines the claim that virtual reality is more authentic than earlier media. The wire, however, turns out a dangerous medium. Two characters have their brains fried through the improper use of the wire, and Lenny himself is addicted to watching wire tapes of his old girl friend instead of getting on with his life. Although the wire does record and help to expose an important political murder, it is technology that is ultimately overcome and discarded in the film.

In several tourdeforce scenes, including the very beginning of the film, the experience of the wire is depicted by a lengthy continuous, first-person point of view camera shot. The viewer sees what the wearer of the apparatus sees. When the wearer takes off the headpiece and returns to the "real" world, it is a filmic world, as represented through traditional Hollywood continuity editing. Film as a representational practice subsumes and ultimately dispenses with the new technology, when Lenny gives up his obsession for his girlfriend and her tapes. In this sense, Strange Days not only depicts, but also exorcises film's anxiety over new media. Strange Days assures us as filmgoers that the apparent immediacy of new media is a dangerous illusion, an unnecessary addiction. ${ }^{12}$

11. Ellen Strain, "Virtual VR," Convergence, Vol. 5, No. 2, summer 1999, p. 10-15.

12. Unlike film, television does not seem to feel a challenge to its representational practice from digital media (even though the economic threat to broadcast television posed by games as home entertainment is at least as great as the threat to traditional film). The holodeck first appeared on the television series, Star Trek: The Next Generation, where it was a recreational device for the crew. Although the holodeck occasionally involved the crew in dangerous adventures, it was generally regarded as one of the enabling technologies of this future world's progressivist culture. The television series' relentlessly optimistic view of technology carries over to the Star Trek film series (which certainly fits Lenny's characterization as “TV, only better.") Star Trek is a special case. In general, television has generally been more open than film to acknowledging its own hybridity, not as committed to transparent representation. 
The Matrix manages to combine both reactions to digital technology (both appropriation and critique) within a single representational scheme. The film embraces computer graphics and celebrates a visual style that depends on computer compositing: e.g. the famous techniques of $360-$ degree camera pans, the slow-motion effects, and digital reconstructions of human figures through motion capture. On the other hand, the Matrix itself is a perfectly insidious virtual reality. If the wire in Strange Days is a device for individual hallucination, the Matrix is a mass hallucination for (almost) all humans, who are actually maintained foetus-like in vats. In a key scene about halfway through the film, Morpheus describes the human condition to Neo. It is a two-person conversation that is similar to the Lenny's pitch scene in Strange Days, except that Morpheus is not trying to sell Neo on the advantages of the Matrix technology, but rather to enlighten Neo and take him out of the Matrix. The Matrix, claims Morpheus, is a "prison for the mind," although it offers a more attractive illusion than the reality of a postapocalyptic world in which intelligent machines enslave humans. More successful than its two sequels, The Matrix manages to engage the viewer with a warning about the danger of digital technologies which is neither entirely serious nor entirely to be dismissed.

The less well-known film eXistenZ, by David Cronenberg, does the same. It expresses its anxiety about new digital media without seeming dogmatic, by finding a register somewhere between satire and melodrama. eXistenZ takes place not exactly in the future, but in a special time and place where the digital game has been perfected as an organic technology that unites with the player's body. The result is again a perfect virtual reality. The film begins with a test session for a new game. A focus group of game enthusiasts plug in, and the play begins. There follow repeated shifts between levels of representation: between the experience of the game and the physical world. Because the game technology is a perfect $\mathrm{VR}$, the game-world is represented by the same filmic techniques used for the physical world. In fact, few if any computer graphic special effects are needed in eXistenZ, because the visual logic of traditional film applies to both its worlds. As a result, the characters and we as viewers can never be sure where the game ends and reality begins. The film suggests the danger that game technology poses in compromising our ability to locate the real. The violence that erupts in the film is the result of various characters' disputes over the construction of reality. In the end, back in the test session, two game players (and vicariously the film's director) apparently take revenge by assassinating the game designer in punishment 
for what they call "the most effective deforming of reality." The reality of even this act of violence is called into question, when the two assassins point their pistols at the guard at the door, who asks skeptically: "Are we still in the game?"

\section{COMPUTER GAMES}

eXistenZ explicitly posits games as a new media form whose representational practice is seductive and dangerous. Recently, Games Studies has emerged as a new field, ${ }^{13}$ and some media theorists specifically argue for games as the form that will remediate film. Such theorists generally agree that the new form demands a changed relationship to the user (who is no longer a mere viewer) - that the digital medium is essentially "interactive" or "participatory." Interactivity is offered as way of refashioning the apparatus and therefore the spectacle of film (and television). Interactivity in digital media gives the player/user the opportunity to intervene in the control of 1 . point of view (which through editing is taken as the defining characteristic of mainstream cinema), 2. temporal flow (which is the defining characteristic of television), or 3 . the narrative structure itself (important for various forms of film and television). In place of a single, linear story, the player/user can intervene to change the order and pace of presentation, the elements, or the outcome of the story. New media theorists argue that with digital technology the viewer/user is no longer a passive consumer of images but rather an active participant in constituting the spectacle. It is this potential for participation, they would argue, that permits digital media to aspire to the authentic.

How film is responding to this aspect of digital media? There were a few attempts to make theatrical film presentation interactive through immediate viewer feedback: the best-known example was Sony's Mr. Payback: An Interactive Movie (Bob Gale, 1995). These experiments have not led to any generally adopted technology. Instead, filmmakers have chosen to treat interactivity as a trope within the traditional apparatus of film. For example, one could argue that a film like Memento (Christopher Nolan, 2000), which presents its scenes in reverse chronological order, requires the viewer to play the role of director or editor and actively to construct or reconstruct the story. In the films that we have already discussed, however, interactivity is allegorized as part of the danger of digital media. The emphasis is on the danger of creating a virtual reality that

13. See the online journal Games Studies: The International Journal of Game Research, <http://www.gamestudies.org $>$. See also Noah Wardrip-Fruen and Pat Harrigan, First Person: New Media as Story, Performance, and Game, Cambridge, Massachusetts, MIT Press, 2004. 
looks and feels like the physical world, and interactivity is assumed to be part of the illusion of transparency. When Lenny in Strange Days praises the wire, his tag line ("you're doing it, you're seeing it, you're hearing it, you're feeling it") suggests that the perceptual experience is so compelling that the user feels herself to be participating in and initiating the action. Contrary to Lenny's pitch, however, the wire does not allow for any authentic participation; it substitutes the perceptual immediacy of someone else's life for active participation in one's own. What Lenny himself seeks is the presence (or copresence) of his former lover, which the technology promises but can never deliver. Likewise in The Matrix, true relationships are impossible inside the virtual reality constructed by the machines; Neo's and Trinity's love happens in the real, if dystopian, physical world.

\section{(CO)PRESENCE, NARRATIVE, AND DIGITAL TECHNOLOGy}

In historical terms it is ironic that films like Strange Days and The Matrix should criticize digital media for failing to deliver on the promise of (co)presence. William Uricchio has shown how the desire for presence was a feature of late 19th century fantasies of a televisual technology. ${ }^{14}$ Enthusiasts imagined a device that would enable viewers in their drawing rooms to experience distant events (sports, concerts, etc.) and to communicate with others at a distance. Film technology was not suited to the goals of copresence and intersubjective communication, for the simple reason that film cannot be "live." Film could satisfy the desire for immediacy only in the sense of allowing the viewer a visual (and later auditory) experience of another place. This was the effect both of the earliest films (such as those of the Lumière brothers) with their recording of everyday events and of the films that Tom Gunning has called the "cinema of attractions." ${ }^{15}$ As Uricchio points out, the early film form, the actualité was a doomed attempt to rival the immediacy of the popular press. The technology of film (the projection of prerecorded images) guaranteed that the viewer could not be seeing events as they happen. Although film offers itself as if present, we as viewers always know that what we see must be a record of the past. By the 1910s and 1920s, mainstream filmmakers (and their large audiences) had decided that film should be a new

14. See William Uricchio, “Technologies of Time," in Jan Olsson (ed.), Visions of Modernity [working title], Berkeley, University of California Press, [forthcoming], and William Uricchio, "Phantasia and Technè at the Fin-de-siècle," in this volume, p. 27-42.

15. Tom Gunning, "The Cinema of Attractions: Early Film, Its Spectator and the Avant-Garde," in Thomas Elsaesser, Adam Barker (ed.), Early Cinema: Space, Frame, Narrative, London, British Film Institute Publishing, 1990, p. 56-62. 
form of storytelling, that film offered authenticity and immediacy of experience through the techniques of visual narrative. It was left to television to attempt to fulfil the fantasy of copresence. Television (and radio) did eventually achieve immediacy and presence in the sense of the "live" broadcast, although the network broadcast system prevented both television and radio from achieving the goal of widespread, two-way communication. In any case, it might be said that, in providing popular culture with an experience that it found satisfyingly transparent and authentic, narrative film distracted early zoth century culture from its fantasy of copresence.

Today film is confronted with digital technologies that new media theorists characterize as both capable of transparent representation and supporting copresence. In this sense, virtual reality can be seen as the following in the line of television and therefore challenging film's version of immediacy. Presence is the name of the premier journal for virtual reality, and achieving copresence and "social presence" (what humanists would call "intersubjectivity") is a major research area among computer specialists in VR. ${ }^{16}$ At the same time, some new media theorists see new digital media forms-in particular, an interactive and immersive form of computer game-as the successor to film as a narrative medium. Without acknowledging the historical precedent that we have been discussing, such theorists are in effect claiming that virtual reality can reunite and finally make good on the two great promises of 19th and zoth century technologies of visual representation: the promise of immediate two-way communication in television and the promise of authenticity of representation in narrative film. To say that digital games will be the film of the 21st century is therefore only half of the claim; the other half is that, because they are immersive and interactive, digital games will be the television of the 21st century as well. It is significant that new media enthusiasts use both terms "interactive cinema" and "interactive television" (almost interchangeably) to describe their idealized medium. The ultimate goal remains the holodeck - a virtual environment that embodies a seamless story-world and enables one human to be present (and two or more humans to be copresent) in it.

Meanwhile, mainstream film disputes both claims for digital media. Denying that digital technology can achieve copresence, film continues to offer a metaphoric copresence through narrative identification, that is, by putting the viewer into intimate contact with the main character. And film also denies

16. See, for example, the original article by Thomas B. Sheridan, "Musings on Telepresence and Virtual Presence," Presence, Vol. 1, No. 1, winter 1992, p. 120-126. 
that interactivity (e.g. user control in a digital game) can represent the "real" more effectively than a good linear narrative. Film still uses continuity editing (although with a somewhat greater tolerance for fragmentation) to achieve transparency; a film is still presented before a spectator who is situated outside looking in as in the theatre.

\section{INTERACTIVITY AND THE DVD}

The insistence by mainstream film to achieve presence through narrative identification remains quite strong. However, in recent years, there is some evidence of willingness to admit a broader range of representational styles through the use of computer graphics. A new style may be emerging in films that situate live actors in a space that is frankly acknowledged to belong to a different visual order. Two recent examples are Sky Captain and the World of Tomorrow (Kerry Conran, 2004) and Sin City (Frank Miller, Robert Rodriguez, 2004), in both of which actors perform in front of blue screens or on minimal sets and computer graphics fill in the world. There is no attempt to convince the viewer of authenticity of the worlds depicted: these are highly stylized spaces drawn from the pages of comic books. Even in these cases, however-perhaps especially in these cases-the goal is still to fashion a seamless visual whole. The style of the film Sin City perfectly matches the dark vision of the original comic book: the film is probably the most faithful remediation of a comic book in the history of this genre.

A more important force for hybridity is the development of DVD technology. When a film is transferred to DVD, the user/viewer can exercise control-at the very least, by accessing a menu to skip directly to individual scenes or "chapters." In many DVDs, there may be an added soundtrack, so that the viewer can choose to listen to the soundtrack as presented in the theatre or to the director's comments. When the DVD includes deleted scenes or even alternate endings, the viewer can assert some control over the course of the narrative of the film to some extent. On the other hand, even when there are alternate scenes and endings, the linearity of film is not seriously challenged. The viewer still has a sense that there is a canonical order to the movie-the one that sometimes plays by default (by simply inserting the disk in the player without making menu choices). The viewer's interventions become experiments within and around this canonical order. The DVD allows a kind of synoptic view of the film-as if the viewer could examine the whole film and its possible versions simultaneously. The DVD offers this synoptic view as an alternative to the "natural" way to view the film, which remains as the grounding representation, the home base, for all the forays that the user may make through the DVD. 
The DVD of Mike Figgis' Time Code (2000) is an example that suggests the potential of this new media form. Hardly a conventional film to begin with, Time Code nevertheless is an example of Hollywood cinema in the sense that it was filmed in and about Hollywood and features a number of recognized stars (Time Code in fact belongs to the genre of films that critiques the film industry itself). Four digital video cameras were used to record four concurrent strands of the story in "real time," and all four strands are presented simultaneously, each occupying one quarter of the screen. The result is still a linear visual experience, on the DVD as in the theater. Although the viewer can choose at any time to attend to any one of the four quadrants, the videos always continue to stream in all quadrants. In the theater version, the director controls the viewer's experience largely through the sound mix. By emphasizing or presenting exclusively the sound of one of the quadrants, the director effectively compels the viewer to attend to that quadrant. The DVD, however, allows the viewer to control the audio mix: the viewer can choose at any time to switch the sound focus from one quadrant to another. In this case the viewer becomes the director or sound editor, deciding how the multiple sound tracks will be linearized.

Time Code shows how DVD technology can blur the line between the traditional film and the computer game. Recent generations of video game boxes (PlayStation 2, XBox) can even function as DVD players, in which case the viewer uses the game controller as a remote to control the DVD. This rapprochement between video game and Hollywood film is not difficult to understand on an economic level in some cases. For example, Sony Corporation makes the PlayStation game box and also owns Columbia and Tristar Pictures, major distributors of Hollywood films. In other cases, however, there is still economic as well as cultural competition. Film still represents the primacy of linear narrative and character, where computer games foreground the importance of interactivity, usually defined by the perceptual and motor skills of the gamer. The DVD in turn is still regarded (and marketed) as an extension of the medium of film. The viewer/user perceives the DVD as holding a movie, to be enjoyed fundamentally as a linear experience. By offering the viewer the opportunity to play the role of editor or director in highly constrained ways, the DVD in fact co-opts the viewer into the director's view of the film. If the apparatus of the cinematic theater positions the viewer in such a way as to identify with (the gaze of) the main character, the DVD adds a second level of identification - a carefully scripted identification with the needs and concerns of the director or producer of the film.

One can imagine that the current DVD is a first step along a path to new multilinear forms of representation that combine techniques now found 
separately in traditional film and the computer game. So far, however, the DVDs produced by the film corporations have been cautious in introducing elements that might undermine the canonical order of film. Meanwhile, both film and computer games have continued to favor the representational strategy of transparency. Film is committed to continuity editing, while computer games are still often measured by the goal of "photorealistic" display. That is, game designers are trying to make their digital characters and settings look more and more like live-action film or (in the case of sports games) television.

\section{HYBRIDITY IN TODAY'S MEDIA ECONOMY}

Richard Grusin has recently argued for another way in which even mainstream film is becoming hybrid-through its marketing and consumption as part of networks of media forms. Grusin argues that this complex of forms (theatrical release, DVD, game, website, blogs, etc.) should be understood as constituting a new kind of cinema-what he calls (on analogy with Gunning's cinema of attractions) the "cinema of interactions." 17 This is an important insight, and in the long run we might well see mainstream film rethinking its cyberphobia. For the present, however, cinema still seems content to allow itself to be constructed as "late." It admits forms of reflectivity, such as the DVD, as long as they do not ultimately challenge linearity and transparency as its foundation.

Thus far, too, this strategy on the part of film has been effective. Filmmakers have sometimes even managed to transform their anxiety about the threat of digital forms into blockbuster hits such as the Matrix trilogy. The success of film (and conventional television) ensures the health of our hybrid media economy, which is filled with various media forms. The older forms of television and film drama and comedy continue to thrive. New forms (computer games) also thrive, while other forms (digital art) carry on the avant-garde tradition that once belonged to film. We have not seen anything like the takeover of a univocal digital media world, which the enthusiasts for new media have been predicting and most traditional filmmakers have been dreading. It is not simply that the holodeck is a technical chimera-so far off that we cannot even discern the technological path to that goal. It is not clear that our culture wants the holodeck, or rather that our culture would choose to have only the holodeck, as opposed to a wealth of hybrid media forms.

17. Richard Grusin, "The Cinema of Interactions: DVDs, Video Games, and the Aesthetic of the Animate," in James Lyons, John Plunkett (eds.), Optical to Digital: Excavating Multimedia History, Exeter, University of Exeter Press [forthcoming 2006]. 